\title{
Theoretical and methodological aspects of assessing the impact of migration flows as a consequence of the bologna process on the security of the state
}

\author{
Oleg N. Slobotchikov, Zarina R. Bitieva, Mikhail V. Shatokhin", Elizaveta V. Shiianova \\ NANO HE Institute of World Civilizations, Leninsky Prospekt, 1/2k1, Moscow, Russia
}

\begin{abstract}
The article presents theoretical and methodological aspects of assessing the impact of migration flows caused by the participation of a number of states in the Bologna Process on the security of the state. The research carried out by the authors make it possible to substantiate the relevance of the development of methodological tools for the impact of migration processes on the security of the country. Since inclusion in the Bologna Process implies an increase in migration flows. The implementation of the methods presented is confirmed by the results of its practical adaptation based on a comparative interstate analysis. The key advantages of the methodology developed by the author are the ability to dynamically assess the effect of migration management in the country for a certain period, which should become the main one for adjusting government decisions in this area of regulation, along with the formation of reasonable conclusions about the positive or negative impact of the migration on the level security, based on the absolute value of the migration effect index.
\end{abstract}

\section{Introduction}

One of the most pressing trends in the development of the current global economy is globalization, which has a significant impact on both the change in the content of the global economy itself and the development of national systems. The impact of globalization on the existing processes in the present-day world is extremely multifaceted. One of the main aspects is the extended border crossing, taking into account both and political factors. The opening of borders and even, in a certain sense, continents provided a vital impetus for the activation and development of migration processes. Various levels of socio- development of states, geopolitical instability in certain regions, and general patterns of the international division of labor have become extra incentives to boost up the migration. The essential characteristics of migration make it possible to identify both positive and negative impacts on donor and recipient countries. There were periods when migration as a global phenomenon on an international scale had a radical impact on the change in the level of

\footnotetext{
*Corresponding Author. Email: shato-hinm@mail.ru
} 
socio- development of a particular state. It might change the characteristics of its political and national-ethnic structure. Such kind of changes within under-migration-countries cannot fail to be of concern. Given conditions require effective policies to manage them. In this regard, government agencies along the countries are developing and implementing large-scale migration management programs. The increased level of relevance of the implementation of measures of state regulation in this area is caused by the significant impact of migration on the state security. Achieving the required and the highest possible level of security is a strategic and priority target for any state. Better-managed migration is one of the most key factors in a set of measures to achieve it. The high level of correlation between migration and the country's security requires the development of a capacious methodological toolkit that allows, on a scientific basis, to carry out a verified assessment of migration impact on the changes in state security.

The objective of this research is to assess the theoretical and methodological aspects of the migration processes' impact on the security of the state. Achieving the objective requires solving the following range of tasks:

- to substantiate the relevance of the development of methodological tools for the impact of migration processes on the security of the country;

- to highlight a set of criteria for determining the scale and intensity of migration processes at the national level;

- to form some elements of an integrated approach to assessing the impact of migration processes on the security level of the country;

- to carry out a practical adaptation of the developed methodology based on a comparative interstate analysis.

\section{Materials and Methods}

The methodological basis for the implementation of this paper were some general scientific research methods, among which it is necessary to highlight research, analytical synthesis, scientific abstraction, statistical, -analytical, monographic, selective observation. The use of the specified set of methods will make it possible to form a reliable assessment of the impact of the intensity of migration processes on the level of security of the state. The developed methodological toolkit will create the foundation for a deeper scientific study of the variability of security under the influence of the migration scale. That is one of the most significant phenomena of the modern world economy in the context of globalization.

The methodology developed in the scientific paper will be adapted, regarding the use of a reliable statistical base of publicly available sources.

\section{Results}

The security of the state on the current globe scale with its many threats is one of the key factors in making managerial decisions at the state level. security is one of the most relevant elements of such a capacious concept as national security. The adoption of a wide range of and political decisions by the Governments among the countries is conditioned by the desire to achieve the highest possible level of security. The essence of security has been studied for a long by various authors. The content of the article is disclosed by the most fundamental interpretation of this phenomenon. Some authors propose to consider the interpretation of the essence of security through the prism of the stability of the state. This point of view, in particular, is being covered in the publication by Akhiyalov A.U. [1, p.31]. security is the ability of the state's economy to function progressively within the framework of existing international relations and to be resistant to fluctuations in the global 
environment. Thus, in this approach, the main criterion for ensuring the necessary level of security of the state is the degree of the national system's stability, considered in conditions of turbulence of external factors.

Another approach to disclosing the essence of a country's security bears an evolutionary nature and is determined by the level of intensity of basic processes within the country. Certain aspects of this approach are, to one degree or another, considered in a scientific article by Orlovskaya T.N. [7, p.21]. Based on the synthesis of the conceptual foundations of this approach, it can be concluded that security is characterized by the degree of development intensity of crucial financial, , and innovation-investment processes in the state. Those are expressed in the rates of growth, taking into account the available resource potential and the quality of its use.

The third approach to the essence of security allows us to consider this phenomenon concerning the degree of independence of the state from external influence in the financial and aspects. In this case, security is the ability of the national system to effectively develop on the principles of independence and self-sufficiency in the absence of critical dependence on external sources of funding or resource bases, but taking into account the communication activity within the framework of international relations.

The interpretations presented in the research make it possible to form a comprehensive opinion on the essence of the security of the state. Each of the approaches presented reflects important aspects of ensuring security, but gives a complete and comprehensive picture of it. The author's view on this problem is that security is a complex concept that includes a triad of elements in the form of resistance to external factors, achieving resource and financial and independence from external sources, and ensuring stable rates of growth. The cumulative development of these components will contribute to an increase in the level of the country's security.

The synthetic nature of security leads to the fact that its level is significantly influenced by a large number of factors. Migration is one of the most significant factors affecting all aspects of security. The essence of the concept of migration in $\mathrm{s}$ is, by and large, unambiguous. Migration is the movement of fairly large groups of people from one region to another for a long period to create conditions for stable living, labor, and income [3, p.35].

The researchers are focusing on the issue of the migration processes' influence on the level of security of the country. Most authors note a high level of correlation between the intensity of migration and indicators of the state's security. As noted by N.P. Sheveleva [9, p.57], the diagnosis of the impact of labor migration on security should be carried out taking into account their division by status into donor and recipient countries. Regarding the change in the status of the state in migration relations, different effects of their influence on the level of security are formed. The so-called "quality" of the migration flow is of key importance for assessing the direction of the impact of migration on the security of the state. In general, the quality of the migration characterizes the volume of intellectual potential and the cost estimate of the labor force transferred to it. Taking into account the essence of this concept, it can be noted that the migration flow, within which the movement of highly educated labor resources capable of performing skilled labor tasks, can be considered as "qualitative". Since the existence of migration is an integral characteristic of the current world economy in the context of globalization, one of the key tasks of the Government is to create conditions for the constant "quality" growth of the incoming migration. The influx of skilled labor contributes to the growth of the security of the state, and the processes associated with the "brain drain", on the contrary, adversely affect its level. In general, the mirror image of the migration influence processes on the condition of donor and recipient countries' security. 
Summarizing the materials of scientific publications [4, p.127], [5, p.37], [2, p.63] made it possible to identify the main directions of the influence of migration processes on the security of the state, which is displayed in Figure 1

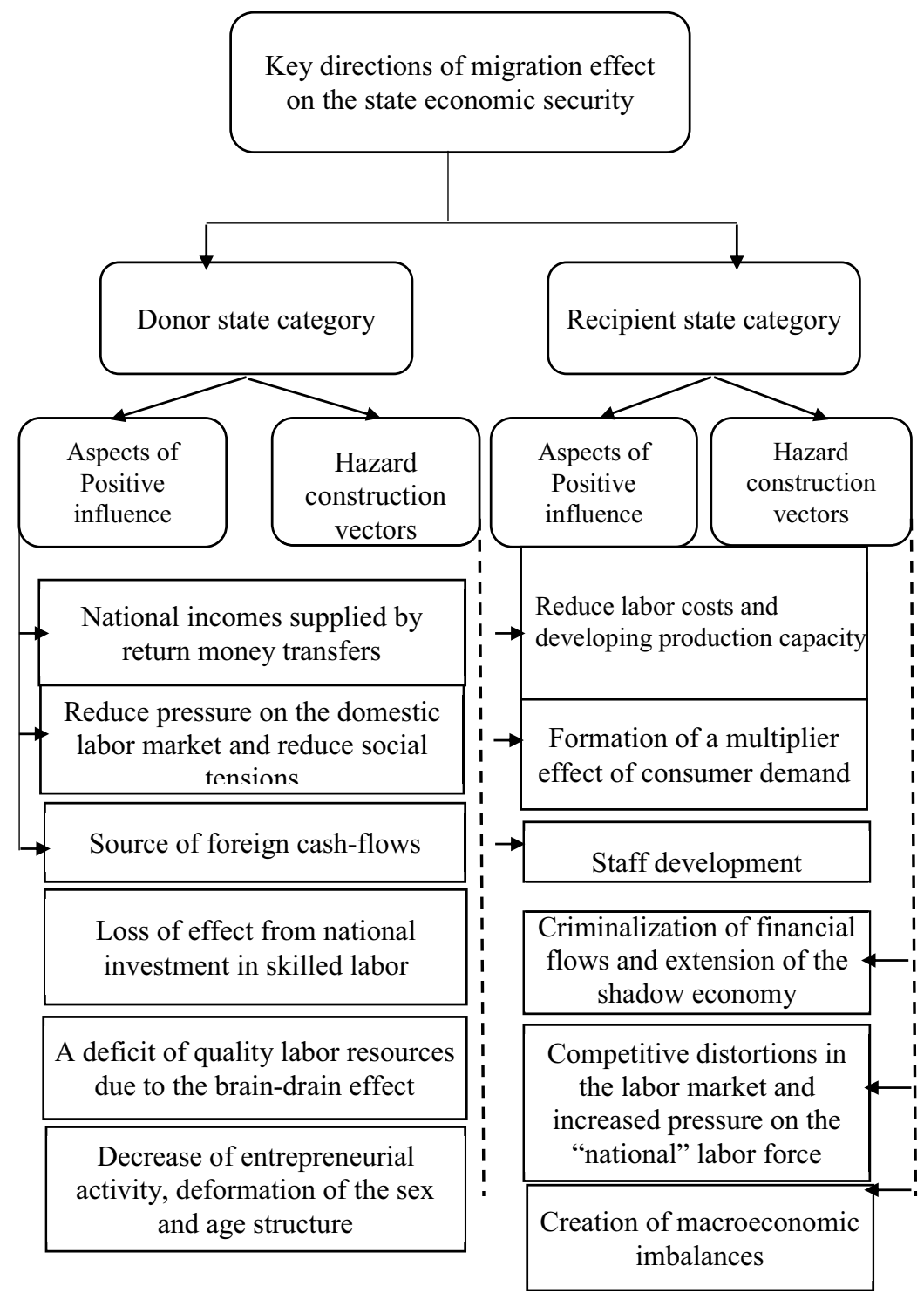

Fig. 1. The main directions of the impact of migration processes on the security of the state

The classification of aspects of the positive impact and vectors of the hazard construction of migration processes on the security of the state, summarized in Figure 1, whereas the correlation of donor and recipient countries, depicts the multiplicative nature of this impact. Moreover, according to N.A. Propel [8, p.137] the multiplicativity of this impact is manifested not only in a wide range of effects but in the time horizon. The results of migration processes can have ripple consequences for the security of the country, both tactically and strategically. 
Several basic tools are used in the scientific literature to determine the vectors of the impact of migration processes on security. Considering the author's position, Figure 2 shows the correlation matrix of the impact of migration processes on security.

\begin{tabular}{|c|c|c|c|c|c|c|}
\hline & \multicolumn{6}{|c|}{ Strength and Degree Assessments of impact on security } \\
\hline \multirow{3}{*}{$\begin{array}{l}\mathrm{C} \\
\mathrm{o} \\
\mathrm{r} \\
\mathrm{r} \\
\mathrm{e} \\
\mathrm{l} \\
\mathrm{a} \\
\mathrm{t} \\
\mathrm{i} \\
\mathrm{o} \\
\mathrm{n}\end{array}$} & Labor & $\begin{array}{c}\text { Increase the } \\
\text { capacity of the labor } \\
\text { market } «+» ; \\
\text { Decrease the labor } \\
\text { potential } «-»\end{array}$ & & & & \\
\hline & Intellectual & & $\begin{array}{l}\text { Progressive staff } \\
\text { development } «+» ; \\
\text { «Brain drain» «-» }\end{array}$ & & & \\
\hline & Social- & & \multicolumn{2}{|c|}{$\begin{array}{l}\text { Consumer effect } «+» ; \\
\text { Social tension rise } «-»\rangle\end{array}$} & & \\
\hline $\begin{array}{l}\mathrm{a} \\
\mathrm{c} \\
\mathrm{t}\end{array}$ & Financial- & & & \multicolumn{2}{|c|}{$\begin{array}{c}\text { Capital inflow «+») } \\
\text { Criminalization of capital } \\
\text { flow «-» }\end{array}$} & \\
\hline $\begin{array}{l}\mathrm{O} \\
\mathrm{r} \\
\mathrm{s}\end{array}$ & Demographic & & & & \multicolumn{2}{|c|}{$\begin{array}{c}\text { Extended use of capacity } \\
\qquad «+» ; \\
\text { Demographic } \\
\text { disproportions } «-»\end{array}$} \\
\hline
\end{tabular}

Fig. 2. Correlation matrix of the migration processes impact on the security

The matrix presented in Figure 2 allows, based on an expert method, to identify the most significant aspects of the impact of migration processes on the security of the country, as well as to assess the degree of relevance and significance of this impact, according to the point-weighted approach.

The importance of studying the issues of the impact of migration processes on the security of the state requires the development of formalized methodological tools for its quantitative assessment. The solution to this problem is the justification of a set of indicators that allow performing assessment procedures grounded in a reliable statistical database.

Within ehe diagnostics of the processes under study, considering the author's position, it is obliged to develop several groups of indicators. Within each group of indicators, generalizing characteristics should be highlighted, allowing for evaluative comparisons. At the initial stage of the developed methodology, consider the indicators of the intensity of migration processes [4, p. 127]:

- Socially tolerable level:

$$
\text { Lst. }=\frac{\mathrm{M}_{s}}{\mathrm{P}_{\mathrm{t}}} * 10000
$$

here Lst - socially tolerable level;

Ms - recent migrants arrived in the state under the period studied;

$\mathrm{Pt}$ - national population on average under the period studied;

- Emigration rate: 


$$
\text { Er. }=\frac{M_{g}}{P_{t}} * 10000
$$

here Er. -emigration rate;

$\mathrm{Me}$ - the quantity of emigrated flows under the period studied;

$\mathrm{Pt}$ - national population on average under the period studied.

At the next stage of the study, it is necessary to determine the criterion that will be a comparable value for assessing the influence of the intensity of migration processes on the level of security of the state. To develop this criterion, two main qualifications must be used:

- age, which reflects the demographic losses of the country as a result of the existence of emigration flows, or vice versa, the demographic "acquisitions" of the state through immigration;

- intellectual, that is, the "quality" of the migration flow. The intellectual qualification should be built according to the level of education of the migrant and the qualifications of his her labor activity [6, p.57].

To solve the first problem, the age index is adapted to the developed methodology, which is calculated according to the following formula:

$$
\mathrm{Ia}=\frac{A R A}{A M A} \text {, }
$$

here Ia - age index of migration;

ARA - average retirement age within both a donor state and a recipient one to assess the emigration flows;

AMA -average migrant age under the period studied.

For a quantitative substantiation of the intellectual component of migration, it is proposed to use the indicator of the human development index. In our opinion, this indicator most capaciously reflects the generalized "value" of an individual, taking into account a wide range of indicators for the security of the state. If security is considered a complexly formed system, then the human development index embodies most of its elements. The calculation of the total value of the human development index includes the determination of several groups of its constituent indicators. The first in a series of these indicators is the life expectancy index, which determined by the formula given below:

$$
\text { Il.e. }=\frac{\text { Long }-L E \min }{L E_{\max }-L E_{\min }}
$$

here Il.e. - life expectancy index;

Long - actual longevity;

LEmin - minimal life expectancy.

Within the framework of the presented calculation algorithm, the value of this indicator is used at the level of 25 years;

LEmax - maximal life expectancy.

Within the framework of the presented calculation algorithm, the value of this indicator is used at the level of 85 years.

The second indicator that is used to calculate the human development index is the index of the achieved level of education, which in turn is determined based on the product of education indices. The literacy index is determined by the following formula:

$$
\text { Ilit. }=\frac{L t_{\text {act }}-L t_{\min }}{L t_{\max }-L t_{\min }}
$$

here Ilit. - literacy index;

Ltact - a share of the literate population under 15 y.o.; 
Ltmin - the minimum share of the literate population under the age of 15 is assumed to be $0 \%$;

Ltmax - the maximum literacy rate of the population is $100 \%$.

The enrollment index is determined using the following methodology:

$$
\text { Ienrlt. }=\frac{E L_{\text {act }}-E L_{\min }}{E L_{\max }-E L_{\min }}
$$

here Ienrlt. - enrollment index;

ELact (educational level) - the actual value of a share of the population enrolling at the age of 6 to 24 of the total number of citizens in this age group;

ELmin - the minimum value of the enrollment indicator is $0 \%$;

ELmax - the maximum level of enrollment is measured by $100 \%$.

Based on the presented indicators, the formula for calculating the index of the achieved level of education is as follows:

$$
\text { IEL }=2 / 3 * \text { Ilit. * } 1 / 3 * \text { Ienrlt., }
$$

here IEL - a calculated value of the index of attained educational level;

Ienrlt. - enrollment index;

Ilit. - Literacy index.

The third component required to determine the human development index is the real GDP per capita index. The determination of the specified indicator based on the following methodology:

$$
\mathrm{IGDP}=\frac{G D P_{a c t}-G D P_{\min }}{G D P_{\max }-G D P_{\min }}
$$

here IGDP. - real GDP per capita index; power parity;

GDPact - the actual value of the country's GDP per capita, based on purchasing

GDPmin - the minimum value of GDP per capita, based on purchasing power parity, shall be taken by $\$ 100$

GDPmax - the maximum value of the GDP value per capita, based on purchasing power parity, shall be taken by 40 thousand dollars.

The overall indicators presented form the complex system, which constructs a methodological basis for calculating the human development index:

here Ihd - the human development index;

$$
\text { Ihd }=1 / 3 * \text { IGDP. }+1 / 3 * \text { IEL }+1 / 3 * \text { Ile., }
$$

IGDP. - real GDP per capita index;

IEL - the calculated value of the attained educational level index;

ILE. -life expectancy index.

At the final stage of assessing the impact of migration processes on the state security, it is necessary to generalize all the presented components into a single integral indicator, which is designated as the index of the migration impact effect on the state security. The calculation of the migration effect index will be carried out according to the following formula:

$$
\mathrm{IME}=\frac{F_{m i} * I_{a r} * I_{h d}}{F_{d i}{ }^{*} l_{a r}{ }^{*} l_{h d}},
$$

где IME - index of the migration impact effect on the state security;

Ihd - human development index;

Iar - age-related index of migration processes;

Fmi. - migration intensity factor;

Fdi - departure intensity factor. 
The value of this index for each state will have its subjective meaning. An important advantage of the migration impact effect index on security is its comparable nature, which allows making objective interstate comparisons based on the value of the given indicator. The absolute value of the migration effect index is also informative, which allows an answer to the positive or negative impact of migration processes on the security of the country. If the value of the migration effect index is more than one, then this fact indicates a positive influence of migration processes on security. If the value of the studied indicator is less than one, then there is a reverse trend. Practical adaptation of the developed methodology made it possible to determine the values of the migration effect index for individual states at the end of 2019, which are explicated in Figure 3

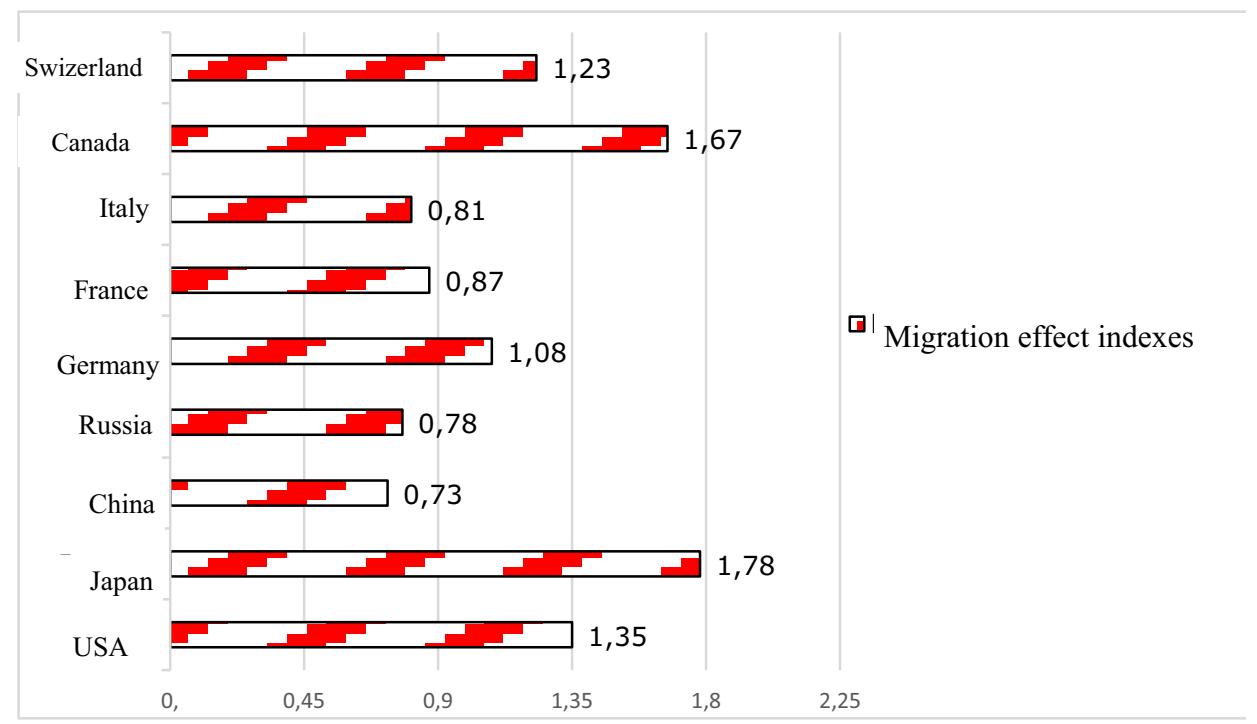

Fig.3. The value of the migration effect index at the end of 2019

* Source: calculated by the author based on these sources [10-13]

Based on the data presented in Figure 3, it can be concluded that even in some developed countries, the value of the migration effect index is less than one, which indicates the negative impact of migration processes on the level of security of the state. The size of the migration effect index in Russia is also less than 1, which is caused by two factors: on the one hand, the existence of a trend of "brain drain", and on the other hand, inflows of low-skilled labor from the neighboring countries.

\section{Conclusions}

The issues of methodological support for assessing the impact of migration processes on security have a high level of scientific and practical significance since they allow optimizing management mechanisms in this area. In the context of the dominance of globalization trends in the world economy at the modern stages of its development, achieving the necessary level of security at the state level is of particular importance. Solving the strategic task of ensuring national security requires taking into account and researching the maximum possible number of factors that influence it. One of the most pressing factors affecting the level of the country's security is migration. The existing conjuncture of the world economy makes it inevitable not only the presence but also the 
intensification of migration processes. In this regard, the governments of practically all states need to develop and implement effective methods in the field of managing migration flows to ensure the required level of security. The use of an effective mechanism for managing the migration process requires the development of a formalized toolkit that makes it possible to assess the intensity of migration, its "quality" and directions of influence on some macro indicators, including security. The presented methodology for assessing the impact of migration processes on the security of the country based on the calculation of the integral index indicator. The index of the migration effect allows in dynamics to assess the effectiveness of management of migration processes in the country within a certain time-frame, which should become the main one for adjusting government decisions in this area of regulation. Based on the value of the migration effect index, it becomes possible to compare the quality of migration management between individual countries. The absolute value of the index of the migration effect is also of important informative value, which allows, taking into account the threshold criterion, to assess the degree of impact of migration processes on the security of the state. If the value of the presented index turns out to be more than one, we can talk about the positive influence of migration processes on security, the value of the index of the migration effect is less than one, gives reason to assert the presence of negative trends in this direction of the factor's impact. Thus, it can be concluded that there is a piece of complex information and the analytical effect that can be formed because of adopting the proposed methodology for assessing the impact of migration processes on the level of security of the country. The list of the disclosed advantages of the integral indicator has a high level of relevance for substantiating programs for managing migration flows within the framework of the national system.

\section{References}

1. A.U. Akhiyarov, A.I.Sharifullina The need to manage labor migration to ensure the economic security of Russia. Innovative economics and modern management, 4, 29-34 (2016)

2. Van Min'yan', E.D. Platonova The role of labor migration in the formation and development of world, Russian and regional labor markets. Bulletin of Eurasian Science, 1, 58-67 (2019)

3. E.I. Vinokurova Management of migration processes in Russia and the EU countries. Management issues, 7, 33-41 (2016)

4. S. Kalyugina Depopulation and external migration as institutional risks of personnel security. Journal of Institutional Studies, 10 4, 125-144 (2018)

5. K.V. Lysak Personnel security as a component of economic security. Academic journalism, 3, 36-41 (2018)

6. V.V. Maslennikov Assessment of losses of the Russian economy from population migration to other countries. Finance: theory and practice, 222 (104), 54-65 (2018)

7. T.N. Orlovskaya Study of the influence of integration processes and globalization processes on ensuring the economic security of Russia. Petersburg Economic Journal, 2, 18-28 (2018)

8. N.A. Pruyel' Migration in modern Russia: scale, main directions and problems // Regionology, 281 (110), 133-158 (2020)

9. N.P. Sheveleva, N.G. Savkina and D.A. Panarina The impact of international labor migration on the socio-economic development of the host country. Society: sociology, psychology, pedagogy, 27, 87-92 (2018) 
10. Gtmarket (2020) Available at: https://gtmarket.ru. (accessed: 3 March 2020)

11. Tadviser (2020) Available at http://www.tadviser.ru (accessed: 10 June 2020)

12. UNECE (2020) Available at : https://www.unece.org (accessed: 13 June 2020)

13. Official site of the UN. Available at: https://www.un.org/ru/ (accessed 20 August 2020) 